\title{
EL DESTINO DE LA PARTICIPACIÓN CIUDADANA LEGISLATIVA: ESTUDIO DE CASO EN LAS INICIATIVAS DE LEY EN NUEVO LEÓN Y LAS PETICIONES E INICIATIVAS LEGISLATIVAS POPULARES EN CATALUNYA
}

\section{THE LEGISLATIVE FATE OF FORMAL CITIZEN PARTICIPATION: CASE STUDY OF THE LAW INITIATIVES IN NUEVO LEÓN AND THE POPULAR LEGISLATIVE INITIATIVES AND PETITIONS IN CATALONIA}

\section{Jorge Francisco Aguirre Sala}

Universidad Autónoma de Nuevo León, Nuevo León, México

jorge.aguirres@uanl.mx

Palabras clave: Parlamento; legislación; autogestión; democratización; elaboración de políticas.

Keywords: Parliament; legislation; self-government; democratization; policy makings.

Resumen: Conocer sobre la admisión y eventual éxito de aprobación, de las peticiones e iniciativas ciudadanas de ley en Nuevo León y en Catalunya es el objetivo. La muestra neolonesa abarca desde la Legislatura LXX hasta la LXXIV, la catalana desde la Legislatura IX hasta la XII. Como aportación metodológica se elaboran fórmulas para dos indicadores: el de destino y el de éxito. Las hipótesis son: (1) el indicador de destino resultará más alto en el caso catalán, (2) el indicador de éxito resultará más alto para el caso neoleonés, (3) en Catalunya ambos indicadores serán superiores en las peticiones en contraste con las ILP, (4) la superioridad de ambos indicadores en las peticiones electrónicas. Los resultados validan dos hipótesis ( 1 y 3), invalidan la (2) y muestran matices en la última. Las discusiones recaban razones de no comparabilidad entre ambas entidades.

Abstract: Knowing the admission or decline and the effective approval of citizen initiatives of law and petitions in Nuevo León and Catalonia defines the objectives. The sample for Nuevo León is ranges from the LXX to the LXXIV Legislature. The case of Catalonia from Legislature IX to XII. As a methodological contribution, formulas are developed to establish two indicators: the destination and the success. The four hypotheses are (1) that the destination indicator will 
be higher in the Catalan case, (2) that the success indicator will be higher for the New Leonese case, (3) that in Catalonia both indicators will be higher for petitions over ILP, (4) the superiority of both indicators in electronic petitions. The results validate two hypotheses (1 and 3), invalidate the (2) and show nuances in the last one. The discussions seek reasons of noncomparability between both entities.

\section{Introducción}

La participación ciudadana formal, a través de propuestas de índole normativa, está alcanzando mayores índices de incidencia política que en décadas pasadas. En sentido laxo, en las propuestas de índole normativa pueden incluirse las peticiones e iniciativas legislativas populares (ILP), según la denominación catalana, y las iniciativas ciudadanas de ley (ICL), al decir de la denominación neoleonesa. No obstante, comparadas con la participación ciudadana electoral y el involucramiento en las consultas ciudadanas, cabe cuestionar su nivel de efectividad.

\section{I Propósito de la investigación}

Establecer la efectividad de las propuestas normativas ciudadanas constituye el propósito de esta investigación. Es decir, determinar la capacidad de éxito de las propuestas ciudadanas ante los legisladores. Esto implica conocer el destino legislativo de uno de los mecanismos de participación formal más apreciado por los ciudadanos, aunque lo ejerzan en menor medida en comparación con otros tipos de participación formal e informal. A la vez, en la teoría y en la práctica, es una de las formas de participación más cuestionada por teóricos, expertos y los representantes políticos. A pesar de lo anterior, el destino legislativo de las propuestas ciudadanas constituye un asunto relevante porque es un eco de la calidad de la democracia, de su correlato con la calidad de la ciudadanía y, sobre todo, de la motivación para participar e involucrarse en los procesos de toma de decisiones en las políticas públicas.

\subsection{Antecedentes y aportaciones}

La tesis que considera a los ciudadanos como incapaces de legislar para sí mismos goza de mucho prestigio dentro de algunas teorías políticas en la democracia moderna. Entre éstas, los referentes usuales aluden a Schumpeter quien considera que: "el elector común no tiene capacidad para discernir sobre los temas públicos de manera autónoma y racional y tampoco pueden obtener soluciones claras para los problemas" (1976: 262). En el mismo sentido que Schumpeter, Przeworski afirma categóricamente: "los ciudadanos no están capacitados para indicar qué debe hacer el gobierno" (1998: 8). En efecto, particularmente el quehacer legislativo posee un alto grado de dificultad, pues los asuntos de las agendas parlamentarias son tan complejos que no pueden plantearse esquemáticamente en instrumentos de participación política como la consulta ciudadana con una simple disyuntiva de "si" o "no". La tarea legislativa tampoco se circunscribe a las escalas locales, como se hace notar por las temáticas que rebasan los presupuestos participativos metropolitanos y los riesgos de inconsistencias en la fragmentación jurídica cuando se involucran distintos niveles de gobierno. 
Problemas como el equilibrio entre el crecimiento económico -que requiere de la explotación de recursos naturales- y los compromisos ecológicos mundiales, las políticas del uso de energías y los riesgos tecnológicos o ambientales; o la explosión demográfica y la migración vinculadas al desempleo: son cuestiones ejemplares tan sofisticadas que, según alega Macpherson, los ciudadanos no pueden generar "las respuestas [que] constituyeran una directriz clara dada al gobierno" (1982: 116). Por lo tanto, no es viable una democracia donde los ciudadanos indiquen a sus representantes los imperativos bajo los cuales legislaran en nombre de ellos, ni siquiera por ellos o a cuenta de ellos. Consecuentemente, Macpherson afirma: "no podemos prescindir de los políticos elegidos" (1982: 118), los representantes políticos deben dominar la agenda pública y legislativa, al tiempo que poseen el monopolio de los procedimientos para tomar decisiones.

Del mismo tenor son las razones que Dahl señala contra la democracia: "la diversidad, el conflicto, la poliarquía, el pluralismo social y organizativo, y la expansión de los derechos individuales" (1993: 259260). En particular el deseo de expandir los derechos individuales, porque tienden a expandirse fuera del marco del bien común o el interés general y atentan contra la democracia (a excepción de los derechos categoriales o diferenciados).

Por supuesto que la imagen del "elector común" aludida por Schumpeter hace referencia a un ciudadano no instruido en la ciencia política, ni en la administración o el derecho público. En contraste con lo anterior, cuando Kelsen considera que una ILP: "consiste en que un determinado mínimo de ciudadanos políticamente capaces puedan presentar un proyecto de ley, a cuya toma en consideración se halle obligado el Parlamento" (1977: 65), se mantenía en el espíritu de convergencia entre un mero proyecto y el quehacer legislativo por oficio. En otras palabras: "no debería de imponerse la presentación de la iniciativa en forma de Proyecto de Ley sino que bastara con que se planteara una idea o propuesta genérica" (Suárez y Welp, 2019: 111), es decir, "indicaba [refiriéndose a Kelsen] que debía ser suficiente con una idea general, sin necesidad de un proyecto elaborado en forma de ley" (Welp, et. al., 2018: 39). Por estas razones doctrinales y otros motivos históricos, casi la totalidad de las democracias contemporáneas reconocen el derecho a realizar peticiones y a proponer iniciativas legislativas por cualquier ciudadano. Por lo tanto, en la práctica de dicho derecho, este análisis pretende aportar, con una muestra de la Comunidad Autónoma de Catalunya, España y del Estado mexicano de Nuevo León, cuál es el destino legislativo de las iniciativas de ley y las peticiones. Ello, a través de la creación de dos indicadores: uno de destino y otro de éxito, que se espera sean útiles tanto para los actores políticos institucionalizados como para la ciudadanía misma en el marco de las intenciones democratizadoras.

\subsection{Preguntas y objetivos de la investigación}

¿Qué capacidad de lograr sus propósitos tienen los ciudadanos cuando elaboran propuestas legislativas ante sus gobiernos? Esta pregunta de investigación tiene, por lo menos, cinco aristas de debate: si las ILP son un mecanismo de democracia directa o pertenece a la democracia representativa, si son una fase del procedimiento legislativo o una forma de ejerci- 
cio del derecho fundamental a participar en los asuntos públicos, si existen causas que motiven una regulación restrictiva, si la regulación jurídica del instrumento promueve o inhibe las iniciativas, si las ILP deben estar al margen del legislador en su regulación y de la ley orgánica, y por último si las ILP han sido abordadas suficientemente en los Congresos y Parlamentos (Fernández, 2019: 13-15).

Las cuestiones anteriores convergen en hacer presentes los deseos ciudadanos en las decisiones de política pública y muestran un ámbito muy amplio. Para focalizar el objeto de estudio, se precisan los siguientes objetivos: explicitar el marco jurídico para realizar propuestas ciudadanas y crear dos indicadores que establezcan, respectivamente, el destino y éxito de éstas.

\subsection{Marco teórico}

Al margen de los interminables debates sobre la capacidad ciudadana de facto para legislar, las ILP se consideran necesarias por varias razones: son "un mecanismo para corregir el funcionamiento excesivamente plebiscitario en el que se habían convertido las democracias representativas contemporáneas" (Pizzorusso, 1980: 133-134), son una institución que auxilia parcialmente a la crisis de representación porque ayudan a los representantes parlamentarios a conocer las demandas e intenciones de la ciudadanía (tal y como lo concibió en el "juicio mediante la discusión" Manin en 1997), a la vez que, contribuyen a un mayor pluralismo político, porque son "una institución que, manteniendo en lo esencial el parlamentarismo, posibilita una cierta injerencia del pueblo en la formación de la voluntad del Estado" (Kelsen, 1977: 115). Por ende, el estado de la cuestión de jure, inicia con el marco jurídico regulatorio, de orden internacional, constituido por Pacto Internacional de Derechos Civiles y Políticos de la Organización de Naciones Unidas (ONU), - suscrito por la mayoría de las naciones del orbe en 1966-, en cuyo artículo 25 otorga a todos los ciudadanos el derecho y la oportunidad de "Participar en la dirección de los asuntos públicos, directamente" (ONU, 1966). La participación directa posee muchas interpretaciones y matices en sus instrumentos, entre otras, las formas de peticiones e ILP. Juristas como Vintró consideran que el carácter formulado de la iniciativa es uno de los elementos que permite distinguir el mecanismo de la ILP de la simple petición, además de permitir un seguimiento de la solicitud por sus promotores (Vintró, 2011).

En lo que corresponde, España no sólo se adhirió al Pacto Internacional de Derechos Civiles y Políticos de la Organización de Naciones Unidas de 1966, sino que el rey Juan Carlos ratificó la adhesión el trece de abril de mil novecientos setenta y siete, según consta en el Boletín Oficial del Estado del 30 de abril de 1977 (BOE, 1977: 9337). La adhesión al Pacto guarda total congruencia con el artículo 29 de la Constitución Española (BOE, 1978: 29318) que otorga el derecho de petición, individual y colectiva, a todos los españoles, a excepción de la petición colectiva a los miembros de las fuerzas armadas. En el caso de México, el Pacto fue suscrito por el presidente José López Portillo el 24 de marzo de 1981 como un acuerdo internacional, razón por la cual, tiene la misma calidad jerárquica que la Constitución. Además, fue promulgado como decreto en el Diario Oficial de la 
Federación el 20 de mayo de ese mismo año (DOF, 1981: 9).

En el caso de México, los artículos, octavo y 35 fracción V, de la Carta Magna reconocen el derecho de petición y obligan a la autoridad correspondiente en dar a conocer, en breve término, un acuerdo escrito al ciudadano peticionario. Para las iniciativas y formación de leyes y decretos, el artículo 71, fracción IV, otorga dicho derecho a los ciudadanos, siempre y cuando la promueva un número equivalente, por lo menos, al cero punto trece por ciento de la lista nominal de electores (DOF, 1917: 149-161).

En lo concerniente al nivel subnacional, la Constitución Política del Estado de Nuevo León otorga a cualquier ciudadano nuevoleonés el derecho a presentar iniciativas de leyes en el artículo 68 (POE, 1917: 41). De igual manera, el derecho de petición es reconocido en el artículo octavo (POE, 1917: 7). Así mismo, para cualquier ciudadano mexicano residente en el Estado, el derecho de peticiones y de iniciar leyes ante el Congreso estatal está salvaguardado por el artículo 36, fracción III (POE, 1917: 21). En adición a lo anterior, la Ley de Participación Ciudadana para el Estado de Nuevo León en el artículo once, fracción $\mathrm{V}$, otorga el derecho a los ciudadanos de presentar iniciativas populares al Congreso y a los Ayuntamientos del Estado sobre proyectos de creación, modificación, derogación o abrogación de leyes o de reglamentos que sean competencia del Congreso o de los Ayuntamientos, respecto de las materias que sean competencia legislativa de los mismos (POE, 2016: 6). Todos los derechos anteriores deben ejercerse en los términos del Reglamento para el Gobierno Interior del Congreso del Estado de Nuevo León
Ahora bien, no huelga hacer hincapié en que el Reglamento para el Gobierno Interior del Congreso del Estado de Nuevo León posee dos estipulaciones dignas de considerarse. El artículo 46 dispone: "Los expedientes que tengan el carácter de iniciativas de Ley o Decreto, que no hayan sido dictaminados en el lapso [sic] de un año a partir de haber sido turnados a comisiones, serán dados de baja por caducidad del listado de asuntos pendientes, sin más trámite, por la Oficialía Mayor" (POE, 1992: 20). De igual manera, para los exhortos, puntos de acuerdo y las denuncias de cualquier naturaleza, dispone que serán dados de baja por caducidad, pero acorta el plazo a un lapso [sic] de seis meses a partir de haber sido turnados a comisiones. Esto implica que, bajo el procedimiento obligado, si una propuesta turnada a una comisión no es dictaminada -por razones justificadas o no-, dentro del plazo reglamentario, entonces el Congreso puede desecharla. En contraste a esta disposición, no existe plazo obligatorio -para las comisiones o el Congreso-, en el cual deba atender y dictaminar las propuestas ciudadanas.

En pocas palabras, las solicitudes ciudadanas ante el Congreso Legislativo de Nuevo León pueden tener tres destinos: 1) en el mejor de los casos, atendidas resueltas y aprobadas, 2) atendidas resueltas y desechadas y, 3 ) pueden no ser atendidas, en cuyo caso podrían permanecer pendientes o, en el peor de los desenlaces, dadas de baja por caducidad del listado de asuntos pendientes, toda vez cumplido el plazo que para ello marca el Reglamento para el Gobierno Interior del Congreso del Estado de Nuevo León.

En lo referente al nivel subnacional en Catalunya, la Ley orgánica 6/2006, del 19 de julio, al reformar del Estatuto de 
Autonomía de Cataluña, establece en la sección cinco del artículo 29: "Todas las personas tienen derecho a dirigir peticiones y a plantear quejas, en la forma y con los efectos que establecen las leyes, a las instituciones y la Administración de la Generalitat, así como a los entes locales de Cataluña, en materias de las respectivas competencias. La ley debe establecer las condiciones de ejercicio y los efectos de este derecho y las obligaciones de las instituciones receptoras" (BOE, 2006: 27273).

Ahora bien, como en el caso mexicano de Nuevo León, el Parlamento catalán está sujeto a un Reglamento de su Estatuto de Autonomía. Ello está fundamentado en el artículo 59, sección siete, del Estatuto que reza: "El Reglamento del Parlamento debe regular la tramitación de las peticiones individuales y colectivas dirigidas al Parlamento. También debe establecer mecanismos de participación ciudadana en el ejercicio de las funciones parlamentarias" (BOE, 2006: 27278). Es decir, contempla la participación ciudadana en el ejercicio parlamentario allende a las peticiones.

Para efectos prácticos, según el Reglamento del Parlamento de Cataluña, es importante considerar la aceptación del trámite de petición, el período que se le otorga a su discusión y el apoyo estatal a los peticionarios. En el artículo 60 se establece explícitamente la Comisión de Peticiones. Ésta, al recibir las peticiones, según la sección tres del mismo artículo, puede remitirlas a cinco instancias: a una comisión parlamentaria competente en la materia, a los grupos parlamentarios para iniciar la promoción de iniciativas, al gobierno o departamentos de gobierno competentes, a cualquier otro órgano de la Generalidad $u$ otras autoridades y al Síndic de Greuges (BOE, 2006: 5786).

Cabe señalar que, al remitir una petición a una comisión parlamentaria competente, cualquier iniciativa o petición, a su vez, puede tener dos destinos. Una posibilidad está en ser remitida la Comisión Legislativa, la otra posibilidad la turna a alguna Comisión Específica, en particular, de estudio, investigación o seguimiento, según el artículo 39 del propio Reglamento (BOE, 2006: 5783). A su vez, alguna Comisión Específica puede remitir a una subcomisión especializada.

En referencia al período de atención que se le otorga a una propuesta, tratándose de ILP, el artículo 140 del texto del Reglamento del Parlamento de Cataluña, en su quinta edición de abril de 2018 (a partir de ahora como Reglamento), concede cuatro meses para debatirlas. En contraste, si alguna petición fue remitida a cualquiera de las cuatro instancias ya descritas, entonces la sección siete del artículo 69 del Reglamento obliga al Parlamento a dar respuesta en un plazo de tres meses. Para el caso de las peticiones, si éstas no fueran remitidas, la Comisión de Peticiones está facultada a archivarla sin más trámite por lo que estipula la sección seis. Ahora bien, el artículo 206 del Reglamento establece que: "Al final de cada legislatura caducan todos los trámites parlamentarios pendientes de examen y de resolución por el Parlamento, salvo los trámites cuya continuidad se establece por leyes específicas". En pocas palabras, existe una diferencia sutil, pero poderosa, entre el procedimiento de una ILP y una petición. La primera, si es admitida a trámite, tiene cuatro meses para ser debatida. La petición, en cambio, puede ser no admitida sin debate alguno o 
puede contar con tres meses para recibir una respuesta. Ambas pueden quedar sin efecto si están dentro de los pendientes parlamentarios al final de una legislatura.

En su quehacer cotidiano, el Parlamento catalán usa las siguientes denominaciones para el destino de las ILP y las peticiones: sustanciada (entiéndase que se aprueba y materializa. Aunque el Reglamento no explicita el concepto, éste apenas se deduce del artículo 85, sección dos), decaída [se entiende que caduca, pierde vigencia o es rechazada; según el glosario del propio Parlamento, significa "Tancament d'una tramitació parlamentària pel finiment de la legislatura" (Parlament de Catalunya, Glossari de termes relacionats amb la tramitació parlamentària, 2018: 2)], en trámite (con opción a hallarse trasladada), acumulada (en el período de una misma legislatura) y disconformidad (entendiendo tal como una oposición a disposiciones del gobierno).

Al comparar los destinos teóricamente posibles según las legislaciones de Catalunya y Nuevo León, puede observarse que en Catalunya existen más denominaciones para indicar el desenlace de las ILP o ILC. Para efectos de esta investi- gación, se considera una similitud entre ambas prácticas, pues las propuestas se aprueban, se reprueban o, en el peor de los casos, se ignoran hasta que pierden vigencia gracias a una disposición jurídica que prevé dicha opción. El Cuadro No. 1 "Comparativo entre Nuevo León y Catalunya de las posibilidades finales de las propuestas" muestra las opciones que existen en cada una de dichas jurisdicciones.

Por otra parte, en lo que concierne a la disponibilidad estatal nuevoleonesa para auxiliar a los ciudadanos en la elaboración de peticiones, iniciativas de ley o reformas, cabe señalar que el Congreso del Estado de Nuevo León cuenta con un Centro de Estudios Legislativos. El artículo 67 del Reglamento para el Gobierno Interior del Congreso le asigna, entre otras obligaciones, atender las consultas ciudadanas con objeto de elaborar las propuestas, denominadas en la fracción X: "proyectos de dictámenes" (POE, 1992: 28).

Por la parte que corresponde a la disponibilidad estatal catalana para auxiliar a los ciudadanos en la elaboración de ILP, reformas o peticiones, cabe señalar que el Reglamento del Parlamento dispone en

\section{Cuadro No. I "Comparativo entre Nuevo León y Catalunya de las posibilidades finales de las propuestas"}

\begin{tabular}{|l|l|}
\hline Catalunya & Nuevo León \\
\hline Sustanciada (puede tener enmiendas) & Resuelta Aprobada (con posibles enmiendas) \\
\hline Decaída & Resuelta Desechada \\
\hline En Trámite (con opción a estar trasladada) & En estudio (Pendientes) \\
\hline Archivadas & Dadas de baja del listado de pendientes por caducidad \\
\hline Acumuladas & ----- \\
\hline Disconformidad con el gobierno & ----- \\
\hline
\end{tabular}

Fuente: elaboración propia a partir de los portales web del Parlamento catalán y el Congreso Legislativo del Estado de Nuevo León [https://www.parlament.cat/web/activitat-parlamentaria/iniciatives-legislatives/iniciativa-legislativa-popular-ilp/index.html y http://www.henl.gob.mx/trabajo_legislativo/ iniciativas/ciudadanas.php]. 
el artículo 142 de asesoramiento exclusivamente informativo y documental en apoyo sólo a las comisiones promotoras. Siempre y cuando la comisión del caso lo solicite a la Secretaría del Parlamento. La sección segunda de dicho artículo prevé la difusión informativa de las ILP con objeto de promover la participación ciudadana durante la tramitación parlamentaria. En el mismo sentido, los artículos 228 a 232 establecen un modelo de Parlamento Abierto.

En atingencia a lo anterior debe reconocerse una trayectoria histórica de esfuerzos en los gobiernos catalanes, como las "Guías breves de participación ciudadana", elaboradas entre 2010 y 2015, por el Departamento de Gobernación y Relaciones Institucionales. En particular, la guía número cuatro: "Guia d'instruments de participación ciutadana a Catalunya" (Martí Mármol y Ezequiel Páez, 2013) que contiene el concepto de la ILP, sus condiciones y procedimiento. En el año 2006, el Departament de Relacions Institucionals i Participació de la Generalitat de Catalunya proporcionaba la "La Iniciativa legislativa popular: guia d'ús". En ese año se reformó la ley vigente desde 1995 que había introducido esta forma de participación ciudadana. Esa guía reconocía la necesidad de auxilio, asesoría y acompañamiento a la ciudadanía, pues "en Catalunya, entre los años 1995 y 2005 sólo se propusieron 6 , de las cuales prosperaron 3" (Saura i Laporta, 2006: 3).

Se ha advertido un sentido laxo o amplio sobre los tipos de las propuestas ciudadanas. En el caso de Nuevo León constituyen iniciativas de ley, de reglamentos, reformas a los mismos, puntos de acuerdo y peticiones. Ante el Congreso de Nuevo León el procedimiento no establece diferendos: toda propuesta sigue el mismo derrotero legislativo (puede consultarse el mapa de flujo del proceso legislativo en: http://www.hcnl.gob.mx/pdf/proceso_legislativo.pdf). En Catalunya, como se deduce de las estipulaciones jurídicas ya descritas, existe la diferencia entre las ILP y las peticiones. Las primeras son de carácter general y las segundas acostumbran a focalizarse en asuntos específicos. Así, por ejemplo, se puede distinguir que las peticiones tratan "....asuntos de carácter no legislativo (una declaración política, una petición de que inste al Gobierno a actuar)" (Illueca, 2015: 1112), para realizar un referéndum o consulta, o cualquier otra acción de su competencia. En lo que se refiere al procedimiento, las peticiones las hay de dos tipos según su vía de presentación; unas son las peticiones que se tramitan de manera tradicional en gestiones documentales editadas, por similitud con la denominación que les da la Generalidad (https://web.gencat. cat/es/tramits/tramits-temes/Peticio-generica), pueden nombrarse "en plazo"; las otras son las peticiones electrónicas. En Nuevo León no existen las condiciones de gobierno electrónico para gestionar las propuestas ciudadanas.

\section{Diseño y método}

\section{2.l Objeto formal}

Los dos objetivos de este estudio pautan sus dos objetos formales: establecer el destino que tienen las propuestas, es decir, indagar si fueron atendidas o resueltas. De haber sido atendidas, entonces conocer su respectiva resolución, es decir, aprobación o rechazo. Para ello, se elaboran las fórmulas de los dos indicadores respectivos: el de destino y el de éxito. 
Es necesario aclarar que por "el destino que tienen las propuestas" se entiende el hecho de haber sido aceptadas a trámite, es decir, resueltas o atendidas. Para establecer su destino, se observa la relación de las atendidas sobre las postuladas (indicador $\mathrm{D}_{1}$ ).

En el segundo indicador se determinará, en el caso de haber sido resueltas, si entonces fueron resueltas aprobadas (sustanciadas, en la denominación catalana). Para conocer los resultados sobre la capacidad ciudadana para elaborar sus propuestas con éxito, es decir, comprobar si al ser resueltas fueron efectivamente aprobadas o sustanciadas, se establece la relación de las propuestas aprobadas sobre las presentadas (indicador $\mathrm{E}_{2}$ ).

En consecuencia, el tratamiento aritmético para cuantificar ambas situaciones se realiza con la fórmula donde en el cociente obtenido del número de propuestas atendidas (indicador $\mathrm{D}_{1}$ ) o el número de propuestas aprobadas (indicador $E_{2}$ ) como un dividendo o numerador sobre el número de propuestas ciudadanas promovidas a modo de divisor o denominador. Es decir, el destino y el éxito de las propuestas se representan con el número de propuestas atendidas y aprobadas, respectivamente, sobre el número de propuestas postuladas por la ciudadanía.

Por lo tanto, el indicador tendrá una unidad de medida que oscila en el coeficiente entre 0 (cero) y 1 (uno), donde uno es el valor óptimo y cero significa lo contrario. Cabe señalar que, en vista de los rezagos en algunos períodos legislativos, la unidad de medida podría superar el cociente 1; pero lamentablemente no se constata dicha posibilidad.

Las fórmulas de los indicadores son:

$$
\mathrm{D}_{1}=\mathrm{a}_{1} / \mathrm{i}
$$

$\left[\mathrm{D}_{1}\right.$ : destino de las iniciativas. $a_{1}$ : iniciativas atendidas. i: iniciativas ciudadanas propuestas]

$$
E_{2}=a_{2} / i
$$

$\left[E_{2}\right.$ : éxito de las iniciativas. $a_{2}$ : iniciativas aprobadas. i: iniciativas ciudadanas propuestas]

Otras formalidades o especificidades sobre el mismo objeto de análisis podrían abordar directamente los casos de defecto. Es decir, cuántas y por qué razones las propuestas ciudadanas quedaron inadmitidas, archivadas o pendientes, para el caso del destino. 0, para el caso del éxito, por qué razones fueron resueltas desechadas (decaídas, en la denominación catalana). Una formalidad que tampoco se aborda está en los casos de modificación o reformulación de las propuestas ciudadanas por parte de los legisladores: cuáles son los motivos y las transformaciones que incidieron sobre las propuestas originales para intentar su aprobación o conseguirla definitivamente. Sin embargo, estas otras formalidades son objeto de indagación con otras metodologías y, por tanto, no se abordan en el presente análisis.

\subsection{Tipo de investigación y fuentes}

Se utiliza un método cuantitativo de cohorte transversal que involucra la recolección de datos por medio de las fuentes catalogadas como oficiales.

Debe advertirse que las fuentes de información del Congreso Legislativo del Estado de Nuevo León no son consistentes. En el sitio web del Congreso están dispo- 
nibles los "Informes" oficiales realizados por la Oficialía Mayor (Disponible en: http://www.hcnl.gob.mx/trabajo_legislativo/informes.php). Estos informes presentan inconsistencias entre sus propias tablas, gráficas y cálculos. Por otro lado, en el mismo sitio web del Congreso se encuentra el sitio que recoge las iniciativas ciudadanas. (Disponible en: http://www. hcnl.gob.mx/trabajo_legislativo/iniciativas/ciudadanas.php). Éste muestra las iniciativas ciudadanas, una a una, clasificadas en el período de cada administración. La información no es consistente entre ambos archivos.

Al igual que el caso de Nuevo León, las fuentes de información del Parlamento de Catalunya lamentablemente no siempre son consistentes. En el sitio web del Parlamento están disponibles las Proposiciones de ley de iniciativa legislativa popular (ILP) (https://www. parlament.cat/ web/activitat-parlamentaria/iniciatives-legislatives/iniciativa-legislativa-popular-ilp/ index.html), las Leyes aprobadas (https:// www. parlament.cat/web/activitat-parlamentaria/lleis/index.html), el Sistema de Información de la Actividad Parlamentaria (SIAP) con las iniciativas tramitadas en el Parlamento y sus respectivas gestiones (https://www. parlament.cat/web/activitatparlamentaria/siap/index.html). Para las peticiones, está la plataforma electrónica con su propio sistema (https://www.parlament.cat/web/participacio/epeticions/ index.html). Por otro lado, la Dirección de Estudios Parlamentarios, a través de su Oficina de Consultas y Atención a los Usuarios, posee un buzón electrónico <direccioestudis@parlament.cat> que recibe y atiende las solicitudes de información. De esta segunda instancia, se obtiene información explícita de índole oficial. La información proporcionada por la Dirección de Estudios Parlamentarios, por vía de su Oficina de Consultas y Atención a los Usuarios, debido a la consulta 191138, respondida el 04 de octubre de 2018, no es consistente con la vertida en los distintos sitios del web site del Parlamento. Al igual que en el caso de Nuevo León, se exponen los resultados provenientes de ambas fuentes de información.

\subsection{Hipótesis}

Sin dejar de considerar las diferencias jurídicas y, sobre todo las procedimentales entre el Parlamento de Catalunya y la Legislatura de Nuevo León, una primera hipótesis es que (1) el indicador de destino resultará más alto en el caso catalán, es decir, los legisladores de Catalunya atienden con más diligencia las propuestas ciudadanas. Esta hipótesis se basa en el supuesto de una mayor tradición política en la esfera pública catalana. En lo referente al éxito de las propuestas ciudadanas, una segunda hipótesis (2) estriba en que resultará más alto el indicador para el caso neoleonés. Esta hipótesis se basa en el supuesto de que las ILP catalanas, una vez atendidas, se enfrentarán a las dificultades de ser turnadas a la Mesa del Congreso de Diputados, como lo marca el artículo 61 del Estatuto de Autonomía de Cataluña (BOE, 2006: 27278).

Las siguientes hipótesis se ubican sólo para el caso catalán: la tercera hipótesis radica en que (3) ambos indicadores serán superiores en las peticiones sobre las ILP. Esta hipótesis se basa en el supuesto de que las ILP son de orden legislativo y alcance general y las peticiones poseen menor alcance legal y menos compro- 
miso demográfico cuando son de orden particular. La cuarta hipótesis (4) apunta a la superioridad de los indicadores de destino y de éxito en las peticiones electrónicas ante las peticiones tradicionales "a plazo". Esta hipótesis se basa en el supuesto de que las condiciones electrónicas aportan una vía de mayor facilidad y de forma más eficaz para ser propuestas.

\section{4 Ámbito de estudio, muestra, variables}

Para el Estado mexicano de Nuevo León, el ámbito de estudio se categoriza bajo la generalidad de las propuestas ciudadanas. El Periódico Oficial del Estado no publica todas las iniciativas resueltas porque entre las iniciativas están leyes, pero también acuerdos, códigos, regulaciones y presupuestos o paquetes fiscales. Por esto se ha advertido que se utiliza la noción de participación ciudadana formal en sentido laxo.

La muestra neolonesa se aborda desde el período de la Legislatura LXX (20 de septiembre de 2003) hasta la Legislatura LXXIV (31 agosto de 2018). Las variables abarcan todo tipo de iniciativas ciudadanas y se dividen, como se ha dicho, en las de destino y éxito para cada uno de los indicadores correspondientes.

El caso de la Comunidad Autónoma de Catalunya distingue las ILP, peticiones y peticiones electrónicas. Por lo tanto, se tratan las propuestas ciudadanas en sentido estricto. La muestra catalana abarca desde la Legislatura IX (16 de diciembre de 2010) hasta la XII (4 de octubre 2018). En lo concerniente a las variables de destino y éxito, éstas se toman en el sentido descrito por los indicadores ya expuestos. A diferencia del caso neoleonés, la Generalidad de Catalunya procede con una Comisión de Peticiones y para las ILP procede de manera ad hoc al asignar Comisiones y subcomisiones semipermanentes dentro de las categorías de la Comisiones Legislativas, de Estudio, de Investigación, más las creadas por Reglamento, por Ley o por razón de Seguimiento.

\section{Resultados}

\section{3.l Destino y éxito de las propuestas ciudadanas en Nuevo León}

La Tabla No.1 "Cuadro histórico del número de iniciativas promovidas, el número de resueltas o atendidas y de éstas el número aprobadas de la L. LXX hasta L. LXXIV, Congreso de Nuevo León. (De acuerdo con la Oficialía Mayor)", muestra los resultados de los "Informes" de la Oficialía Mayor, donde se vierten datos que nutren los indicadores $D_{1}$ y $E_{2}$.

En contraste, la Tabla No.2 "Cuadro histórico del número de iniciativas promovidas, el número de atendidas por L. LXXI hasta L. LXXIV del Congreso de Nuevo León. (Sólo indicador $\mathrm{D}_{1}$ de acuerdo con los archivos del web site, sección "Trabajo Legislativo")" presenta los datos donde esta investigación contabilizó todas las iniciativas una por una. Pero la fuente informativa sólo provee datos si fueron resueltas o no (es decir, atendidas por los legisladores) y no indica si, después de ser resueltas, su destino final fue la aprobación o el rechazo. Por lo tanto, desde la fuente del sitio web, sección "Trabajo Legislativo", no es posible obtener el indicador $E_{2}$. 
Tabla No. l: "Cuadro histórico del número de iniciativas promovidas, el número de resueltas 0 atendidas y de éstas el número aprobadas de la L. LXX hasta L. LXXIV, Congreso de Nuevo León. (De acuerdo con la Oficialía Mayor)”

\begin{tabular}{|l|c|c|c|c|}
\hline Legislatura & $\begin{array}{c}\text { Número de } \mathbf{i} . \\
\text { resueltas/ Número de } \\
\text { i. promovidas }\end{array}$ & $\begin{array}{c}\text { Número de i. } \\
\text { aprobadas/ Número de } \\
\text { i. promovidas }\end{array}$ & $\begin{array}{c}\text { Indicador de destino } \\
\text { (Iniciativas } \\
\text { atendidas) } \\
\mathbf{D}_{1}\end{array}$ & $\begin{array}{c}\text { Indicador de capacidad } \\
\text { ciudadana (Iniciativas } \\
\text { aprobadas) } \\
\mathbf{E}_{2}\end{array}$ \\
\hline $\begin{array}{l}\text { LXX } \\
\text { (20 de sept. 2003- } \\
31 \text { de ago. de 2006) }\end{array}$ & $105 / 143$ & $62 / 143$ & .7342 & .4335 \\
\hline $\begin{array}{l}\text { LXXI } \\
\text { (1 de sept. 2006- } \\
31 \text { ago. de 2009) }\end{array}$ & $125 / 178$ & $43 / 178$ & .7022 & .2415 \\
\hline $\begin{array}{l}\text { LXXII } \\
\text { (1 de sept. de 2009- } \\
31 \text { de ago. del 2012) }\end{array}$ & $58 / 76$ & $\begin{array}{c}\text { Información no } \\
\text { disponible }\end{array}$ & .7631 & Información no disponible \\
\hline $\begin{array}{l}\text { LXXIII } \\
\text { (1 de sept. del 2012- } \\
31 \text { de ago. del 2015) }\end{array}$ & $67 / 178$ & $29 / 178$ & .3764 & .1629 \\
\hline $\begin{array}{l}\text { LXXIV } \\
\text { (1 de sept. del 2015- } \\
31 \text { de ago. del 2018) }\end{array}$ & $78 / 286$ & $29 / 286$ & .2727 & \\
\hline
\end{tabular}

Fuente: Elaborado con información del H. Congreso del estado de Nuevo León, www.hcnl.gob.mx (http://www.hcnl.gob.mx/trabajo_legislativo/informes.php)

Tabla No. 2: "Cuadro histórico del número de iniciativas promovidas, el número de atendidas por L. LXXI hasta L. LXXIV del Congreso de Nuevo León. (Sólo indicador $\mathrm{D}_{1,}$ de acuerdo con los archivos del web site, sección “Trabajo Legislativo")"

\begin{tabular}{|l|c|c|}
\hline Legislatura & $\begin{array}{c}\text { Número de i. resueltas/ Número } \\
\text { de i. promovidas }\end{array}$ & $\begin{array}{c}\text { Indicador de destino } \\
\text { (Iniciativas resueltas) } \\
\mathbf{D}_{1}\end{array}$ \\
\hline $\begin{array}{l}\text { LXX } \\
\text { (20 de sept. 2003 - } \\
31 \text { de ago. de 2006) }\end{array}$ & Información no disponible & Información no disponible \\
\hline $\begin{array}{l}\text { LXXI } \\
\text { (1 de sept. 2006- } \\
31 \text { ago. de 2009) }\end{array}$ & $5 / 6$ & .8333 \\
\hline $\begin{array}{l}\text { LXXII } \\
\text { (1 de sept. de 2009- } \\
\text { 31 de ago. del 2012) }\end{array}$ & 28/39 \\
\hline $\begin{array}{l}\text { LXXIII } \\
\text { (1 de sept. del 2012- } \\
\text { 31 de ago. del 2015) }\end{array}$ & $159 / 205$ & .7179 \\
\hline $\begin{array}{l}\text { LXXIV } \\
\text { (1 de sept. del 2015- } \\
\text { 31 de ago. del 2018) }\end{array}$ & $262 / 369$ & .7756 \\
\hline
\end{tabular}

Fuente: Elaborado con información del H. Congreso del estado de Nuevo León, www. hcnl.gob.mx (http://www.hcnl.gob.mx/trabajo_legislativo/iniciativas/ciudadanas.php).

\subsection{Destino y éxito de las propuestas ciudadanas en Catalunya}

En la Tabla No. 3: "Cuadro histórico del número de ILP promovidas, el número de atendidas o aceptadas y de éstas el número sustanciadas de la L. IX hasta L. LXXII en el Parlamento Catalán", se muestran los datos ofrecidos por la Dirección de Estudios Parlamentarios y su Oficina de Consultas con un corte al 4 de octubre de 2018. Esos datos permiten el cálculo de los indicadores $\mathrm{D}_{1}$ y $\mathrm{E}_{2}$. 
Tabla No. 3 “Cuadro histórico del número de ILP promovidas, el número de atendidas 0 aceptadas y de éstas el número sustanciadas de la L. IX hasta L. LXXIl en el Parlamento Catalán” (De acuerdo con la Dirección de Estudios Parlamentarios)

\begin{tabular}{|c|c|c|c|c|}
\hline Legislatura & $\begin{array}{l}\text { Número de i. } \\
\text { antendidas/ Número de } \\
\text { i. promovidas }\end{array}$ & $\begin{array}{c}\text { Número de i. } \\
\text { sustanciadas/ Número } \\
\text { de i. promovidas }\end{array}$ & $\begin{array}{c}\text { Indicador de destino } \\
\text { (Iniciativas atendidas) } \\
\mathrm{D}_{1} \\
\end{array}$ & $\begin{array}{c}\text { Indicador de capacidad } \\
\text { ciudadana (Iniciativas } \\
\text { sustanciadas) } \\
E_{2}\end{array}$ \\
\hline $\begin{array}{l}\text { Legislatura IX } \\
\text { (16 dic } 2010 \text { a } 2 \text { oct } \\
2012)\end{array}$ & $9 / 9$ & 0/9 & 1 & ( \\
\hline $\begin{array}{l}\text { Legislatura } \mathrm{X} \\
\text { (17 dic } 2012 \text { a } 2 \text { oct } \\
\text { 2015) }\end{array}$ & $5 / 5$ & $3 / 5$ & 1 & .6 \\
\hline $\begin{array}{l}\text { Legislatura XI } \\
\text { (26 oct } 2015 \text { a } 27 \text { oct } \\
2017 \text { ) }\end{array}$ & $1 / 1$ & $\begin{array}{l}\text { Información no } \\
\text { disponible }\end{array}$ & 1 & $\begin{array}{l}\text { Información no } \\
\text { disponible }\end{array}$ \\
\hline $\begin{array}{l}\text { Legislatura XII } \\
\text { (17 ene } 2018 \text { a } 4 \text { oct } \\
2018)\end{array}$ & $2 / 2$ & $\begin{array}{l}\text { Información no } \\
\text { disponible }\end{array}$ & 1 & $\begin{array}{l}\text { Información no } \\
\text { disponible }\end{array}$ \\
\hline
\end{tabular}

Fuente: elaboración propia a partir del oficio de respuesta a la Consulta 191138 de la Dirección de Estudios Parlamentarios.

En contraste a la anterior fuente de la información, si se considera el sitio web del Parlamento catalán, se obtienen los resultados de la Tabla No. 4: "Cuadro histórico del número de iniciativas promovidas, el número de atendidas o aceptadas y de éstas el número sustanciadas de la L. IX hasta L. LXXII en el Parlamento Catalán (de acuerdo con el web site y los micrositios del Parlamento)".

Tabla No. 4 "Cuadro histórico del número de iniciativas promovidas, el número de atendidas 0 aceptadas y de éstas el número sustanciadas de la $\mathrm{L}$. IX hasta L. LXXII en el Parlamento Catalán (de acuerdo con el web site y los micrositios del Parlamento)".

\begin{tabular}{|c|c|c|c|c|}
\hline Legislatura & $\begin{array}{c}\text { Número de i. } \\
\text { antendidas/ Número de } \\
\text { i. promovidas }\end{array}$ & $\begin{array}{l}\text { Número de i. } \\
\text { sustanciadas/ Número } \\
\text { de i. promovidas }\end{array}$ & $\begin{array}{c}\text { Indicador de destino } \\
\text { (Iniciativas atendidas) } \\
\mathrm{D}_{1} \\
\end{array}$ & $\begin{array}{c}\text { Indicador de capacidad } \\
\text { ciudadana (Iniciativas } \\
\text { sustanciadas) } \\
\mathrm{E}_{2} \\
\end{array}$ \\
\hline $\begin{array}{l}\text { Legislatura IX } \\
\text { (16 dic } 2010 \text { a } 2 \text { oct } \\
2012 \text { ) }\end{array}$ & $7 / 7$ & $0 / 7$ & ( & 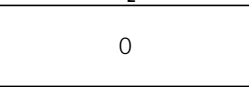 \\
\hline $\begin{array}{l}\text { Legislatura } \mathrm{X} \\
\text { (17 dic } 2012 \text { a } 2 \text { oct } \\
2015)\end{array}$ & $2 / 2$ & $2 / 2$ & 1 & 1 \\
\hline $\begin{array}{l}\text { Legislatura XI } \\
\text { (26 oct } 2015 \text { a } 27 \text { oct } \\
2017 \text { ) }\end{array}$ & $17 / 17$ & $7 / 17$ & 1 & .41 \\
\hline $\begin{array}{l}\text { Legislatura XII } \\
\text { (17 ene } 2018 \text { a } 4 \text { oct } \\
\text { 2018) }\end{array}$ & $7 / 7$ & $4 / 7$ & 1 & .57 \\
\hline
\end{tabular}

Fuente: elaboración propia a partir del sitio web del Parlamento están disponibles las Proposiciones de ley de iniciativa legislativa popular (https://www.parlament.cat/web/activitat-parlamentaria/iniciatives-legislatives/iniciativa-legislativa-popular-ilp/index.html), las Leyes aprobadas (https:/www.parlament.cat/web/activitat-parlamentaria/lleis/index.html), el Sistema de Información de la Actividad Parlamentaria (SIAP) con las iniciativas tramitadas en el Parlamento y sus respectivas gestiones (https://www.parlament.cat/web/activitat-parlamentaria/siap/index.html) 
A diferencia de los resultados expuestos de las ILP, los resultados que se exponen a continuación sobre las peticiones provienen de la respuesta a consulta hecha a la Dirección de Estudios Parlamentarios porque en ninguno de los documentos accesibles en el web site del Parlamento catalán se distingue entre las peticiones presentadas de manera tradicional en plazo y las electrónicas. De igual modo, en el Boletín Oficial del Parlamento, o los textos de trámites de cada expediente, la consulta de expedientes, y el Diario de las Sesiones de la Comisión de Peticiones, sean en versión editada o digital, no se halla información para distinguir si la petición fue postulada por vía tradicional o electrónica. La Tabla No. 5: "Destino de las peticiones presentadas al Parlamento catalán" y la Tabla No. 6: "Destino de las peticiones electrónicas presentadas al Parlamento catalán" muestran por Legislatura los correspondientes indicadores $D_{1}$ y $E_{2}$.

\section{Tabla No. 5: "Destino de las peticiones presentadas al Parlamento catalán”}

\begin{tabular}{|l|c|c|c|c|}
\hline Legislatura & $\begin{array}{c}\text { Número de peticiones } \\
\text { atendidas/ Número de } \\
\text { peticiones promovidas }\end{array}$ & $\begin{array}{c}\text { Número de peticiones } \\
\text { sustanciadas / Número } \\
\text { de i peticiones } \\
\text { promovidas }\end{array}$ & $\begin{array}{c}\text { Indicador de destino } \\
\text { (peticiones atendidas) }\end{array}$ & $\begin{array}{c}\text { Indicador de capacidad } \\
\text { ciudadana (peticiones } \\
\text { sustanciadas) } \\
\mathbf{E}_{2}\end{array}$ \\
\hline $\begin{array}{l}\text { Legislatura IX } \\
\text { (16 dic 2010 a } 2 \text { oct } \\
\text { 2012) }\end{array}$ & $34 / 34$ & $23 / 34$ & 1 & .67 \\
\hline $\begin{array}{l}\text { Legislatura X } \\
\text { (17 dic 2012 a } 2 \text { oct } \\
\text { 2015) }\end{array}$ & $50 / 50$ & $38 / 50$ & 1 & .76 \\
\hline $\begin{array}{l}\text { Legislatura XI } \\
\text { (26 oct 2015 a } 27 \text { oct } \\
\text { 2017) }\end{array}$ & $14 / 16$ & $14 / 16$ & .875 & .875 \\
\hline $\begin{array}{l}\text { Legislatura XII } \\
\text { (17 ene 2018 a } 4 \text { oct } \\
\text { 2018) }\end{array}$ & $5 / 5$ & $0 / 5$ & 1 & 0 \\
\hline
\end{tabular}

Fuente: Información proporcionada por la Dirección de Estudios Parlamentarios en respuesta a la Consulta 191138.

\section{Tabla No. 6: "Destino de las peticiones electrónicas presentadas al Parlamento catalán"}

\begin{tabular}{|l|c|c|c|c|}
\hline Legislatura & $\begin{array}{c}\text { Número de e-p } \\
\text { antendidas/ Número de } \\
\text { e-p promovidas }\end{array}$ & $\begin{array}{c}\text { Número de e-p } \\
\text { sustanciadas/ Número } \\
\text { de e-p promovidas }\end{array}$ & $\begin{array}{c}\text { Indicador de destino } \\
\text { (e-p atendidas) }\end{array}$ & $\begin{array}{c}\text { Indicador de capacidad } \\
\text { ciudadana } \\
\text { (e-p sustanciadas) } \\
\mathbf{E}_{2}\end{array}$ \\
\hline $\begin{array}{l}\text { Legislatura IX } \\
\text { (16 dic 2010 a } 2 \text { oct } \\
\text { 2012) }\end{array}$ & $42 / 42$ & $34 / 42$ & 1 & .80 \\
\hline $\begin{array}{l}\text { Legislatura X } \\
\text { (17 dic 2012 a } 2 \text { oct } \\
\text { 2015) }\end{array}$ & $99 / 99$ & $92 / 99$ & 1 & .929 \\
\hline $\begin{array}{l}\text { Legislatura XI } \\
\text { (26 oct 2015 a 27 oct } \\
\text { 2017) }\end{array}$ & $82 / 82$ & $70 / 82$ & 1 & .853 \\
\hline $\begin{array}{l}\text { Legislatura XII } \\
\text { (17 ene 2018 a } 4 \text { oct } \\
\text { 2018) }\end{array}$ & $12 / 12$ & $0 / 12$ & 1 & 0 \\
\hline
\end{tabular}

Fuente: información proporcionada por la Dirección de Estudios Parlamentarios en respuesta a la Consulta 191138. 


\section{Discusiones}

\subsection{Discusiones sobre los resultados del caso Nuevo León, México}

Un resultado destacado se puede observar en el indicador $D_{1}$ con grandes diferencias entre las dos fuentes de información en lo que corresponde a las legislaturas LXXIII y LXXIV de Nuevo León. Las razones para adoptar el indicador $\mathrm{D}_{1}$ a partir de la información obtenida en el sitio web, sección "Trabajo legislativo" y no de los "Informes" de la Oficialía Mayor son: el sitio web presenta, una por una, todas las iniciativas y sus respectivos archivos, lo que permitió revisarlas, conocer los nombres de los ciudadanos postulantes, contabilizarlas y validarlas. Mientras que los "Informes" de la Oficialía Mayor tienen inconsistencias en sí mismos y, por tanto, dan pauta para sospechar de su validación. Las sospechas se basan en los siguientes hechos: Ios "Informes" de Oficialía Mayor se dividen en distintos períodos aún dentro del tiempo de la misma legislatura, con lo cual, sus cortes presentan complicaciones de continuidad. Si una propuesta ciudadana es secundada por algún legislador, entonces podría contabilizarse doble en las categorías de los promoventes, es decir, tanto por iniciativa ciudadana como por la del representante político que la secunda o avala.

Desafortunadamente, no existe una tercera instancia que aporte evidencia para resolver la ambigüedad en el caso del Estado de Nuevo León entre el listado oficial del web site y los informes de la Oficialía Mayor. La Periódico Oficial del Estado, como corresponde a su naturaleza, sólo publica las leyes resueltas aprobadas y no aporta informes sobre los acuerdos, códigos, regulaciones y presupuestos o paquetes fiscales.
A pesar de la dificultad anterior, la información del sitio web tiene la ventaja de mostrar el número de iniciativas ciudadanas presentadas y las iniciativas resueltas de acuerdo con las principales comisiones legislativas: de Desarrollo Social, de Juventud, para la lgualdad de Género, de Justicia y Seguridad Pública, de Puntos Constitucionales, de Legislación, de Medio Ambiente, de Desarrollo Metropolitano. En términos absolutos, los aspectos públicos del desarrollo social, juventud, género, medio ambiente y desarrollo metropolitano tienen muy baja incidencia. De entre ellos, desafortunadamente el problema de igualdad de género y medio ambiente presentaron la menor atención ciudadana.

Aunado a lo anterior, es notoria la diferencia de interés entre los legisladores y los ciudadanos, pues mientras los ciudadanos inciden más en los puntos constitucionales, la legislación, seguridad y justicia; los legisladores atienden al cien por ciento las temáticas del desarrollo social y el metropolitano. Por otro lado, a partir de la legislatura LXXIII, la sociedad civil ejerció mucha presión para lograr la Ley de Participación Ciudadana (2016). Esta dinámica ha desencadenado no solo la presentación de iniciativas, sino también una actitud gubernamental más abierta y transparente para registrarlas y hacerlas públicas. Como mero dato indagatorio para futuras investigaciones, es interesante hacer hincapié que desde la Legislatura LXXV, el sitio web del parlamento ha presentado nuevas rutas de acceso a la información y nuevos formatos donde se exponen las iniciativas ciudadanas.

La aprobación de Ley de Participación Ciudadana en 2016 parece más explicativa del fenómeno, aunado al hecho de que los partidos políticos en Nuevo León muestran más cercanía y responsabilidad con 
la ciudadanía. Dicha cercanía se atribuye a la pérdida del poder ejecutivo en 2015 , debido al triunfo de un candidato independiente en la gobernatura del Estado.

\subsection{Discusiones sobre los resultados del Parlamento catalán}

La Generalitat de Catalunya, si bien presenta diferencias en sus fuentes de información, éstas pueden interpretarse de distintas maneras. Si se interpreta en base a los indicadores, -hasta donde la información se encuentra disponible-, el indicador $\mathrm{D}_{1}$ se muestra consistente en dos de cuatro Legislaturas.

$E$ El indicador $E_{2}$ muestra una diferencia de coma cuatro puntos durante la Legislatura $X$. No obstante, si se toma este indicador para la Información de la Legislatura $X$ de la Dirección de Estudios parlamentarios y desde la información del web site para las Legislaturas XI y XII, los respectivos resultados son: .6, .41, .57: lo cual indica cierta consistencia y validación. No obstante, debe tomarse en cuenta el disímil número de ILP presentadas en la Legislatura IX y X comparadas con las dos siguientes. Pues según la Dirección de Estudios en las primeras hubo mayor número de propuestas, pero según los datos del web site, el mayor número de propuestas se dieron en las dos segundas. Aunque los indicadores resultan similares, el número de propuestas es notoriamente distinto. Por ejemplo, según la Dirección de Estudios, la Legislatura XI sólo recibió una solicitud, mientras que el web site marca diecisiete.

Cabe puntualizar que la recogida de datos desde el web site, al igual que el caso de Nuevo León, se realizó revisando una por una todas las iniciativas. Por lo tanto, se vuelve a seguir el criterio de adoptar para el indicador $\mathrm{D}_{1}$ la información del sitio web. También porque la respuesta a la Consulta hecha a la Dirección de Estudios Parlamentarios está categorizada según los totales de iniciativas presentadas, en trámite y su finalización, sin remitir a la Memoria de las Comisiones, los documentos del conocimiento del pleno o aprobación y/o la publicación de la Memoria respectiva por Legislatura.

En contraste con las ILP, las peticiones se presentan en mayor número y alcanzan mejor destino y éxito. Resulta notorio que a partir del año 2010 y hasta el año 2017, las peticiones electrónicas muestran auge en sus solicitudes (en ese período fueron 105 peticiones a plazo y 235 peticiones electrónicas) y también un relativo mejor éxito político. El 83.40 por ciento de las peticiones electrónicas en el período referido fueron sustanciadas, mientras que las peticiones no electrónicas alcanzaron el mismo éxito en 71.42 por ciento.

En atingencia a la disponibilidad estatal para auxiliar a los ciudadanos en la elaboración de sus propuestas, en el caso neoleonés, -según las evidencias de los informes y archivos de la Oficialía Mayor-, no se detecta práctica alguna. Por tanto, el Centro de Estudios Legislativos sólo elabora y analiza los dictámenes por encomienda de los partidos políticos.

Para el caso del Parlamento catalán, la posibilidad del Parlamento Abierto según los artículos 228 a 232 del Reglamento del Parlamento, todavía no se encuentra suficientemente instrumentalizado. De igual manera el micrositio web "Escaño 136" (https://www. parlament.cat/web/ participacio/esco-136/index.html), -en alusión a que cualquier ciudadano puede constituirse simbólicamente en el diputa- 
do ciento treinta y seis de los ciento treinta y cinco que conforman oficialmente al Parlamento-, no cuenta con herramientas interactivas para auxiliar a los ciudadanos en la formulación de sus propuestas.

Por otra parte, el micrositio "Escaño 136" estipula que el "debate ciudadano será utilizado durante el trabajo de los órganos tramitadores y quedará reflejado en una memoria anexa a las iniciativas tramitadas, en el que se destacarán especialmente las aportaciones que finalmente se incorporen al texto". Si bien es cierto que el micrositio da acceso a los Diarios de las sesiones donde aparecen las comparecencias, no ofrece evidencias de la memoria anexa donde se destaquen las aportaciones incorporadas al texto final de las resoluciones publicadas en el Boletín Oficial del Parlamento de Catalunya (BOP)

\subsection{Validación de las hipótesis y cumplimiento de objetivos}

La primera hipótesis: (1) que el indicador de destino $\left(D_{1}\right)$ resultará más alto en el caso catalán, los datos de las cuatro fuentes oficiales si la validan. Una evidencia importante para validar esta hipótesis por triangulación está en que los datos de las fuentes neoleonesas son inconsistentes respecto al indicador $D_{1} y$, en contraste, presentan mayor consistencia en las fuentes catalanas.

La segunda hipótesis: (2) referente al éxito de las propuestas ciudadanas que resultará más alto para el caso neoleonés, los datos obtenidos por el indicador $\mathrm{E}_{2}$ muestran que no se cumple. En añadidura, como en el caso anterior, también hay mayor consistencia entre las fuentes informativas catalanas, pues en Nuevo
León sólo se cuentan con los Informes de Oficialía Mayor, dado que la fuente del web site no aporta datos para el indicador.

La tercera hipótesis: (3) que para el caso catalán ambos indicadores $\left(D_{1}\right.$ y $\left.E_{2}\right)$ serán superiores en las peticiones sobre las ILP, los resultados si la validan. Ello, a excepción de un único caso donde el indicador $\mathrm{D}_{1}$ de peticiones en plazo, en la Legislatura $\mathrm{XI}$, se presenta con 125 centésimas menos que las ILP. En la validación de esta hipótesis, cabe suponer que la inferioridad de los indicadores para las ILP obedece al menor alcance legislativo, político y demográfico que poseen las peticiones; ello les otorga ventaja de efectividad.

La cuarta hipótesis: (4) sobre la superioridad de las peticiones electrónicas sobre las editadas en plazo en los indicadores de destino y éxito, los resultados del indicador $\mathrm{D}_{1}$ la invalidan, pues tanto las peticiones electrónicas como las editadas son efectivamente atendidas. No obstante, los resultados atingentes al éxito, indicador $\mathrm{E}_{2}$ muestran que la hipótesis si se cumple.

De las anteriores validaciones e invalidaciones, si se compararan las dinámicas ciudadanas neoleonesas y catalanas en su destino y éxito, se infieren mejores indicadores para el caso catalán. Estos resultados no pueden validar, ni suponer, que el caso catalán muestre mejor rendimiento legislativo, calidad democrática o calidad participativa de la ciudadanía. Para tales efectos deberán considerarse más variables: entre otras, las cinco aristas a debate señaladas al inicio y considerar que respecto a la hipótesis uno (1), el indicador catalán es superior en rendimiento legislativo, pero las legislaturas catalanas han recibido en un período de siete años (diciembre 2010 a octubre 2018) menos ILP y peticiones en conjunto, que las le- 
gislaturas neoleonesas en un período casi similar (septiembre 2009 a mayo 2018), y habría que discernir si en Nuevo León se diferenciaron entre las ICL y las peticiones de cualquier otro tipo (sobre todo, los puntos de acuerdo, que en Nuevo León son recurrentes). Respecto a la hipótesis dos (2) es necesario recordar que el sitio web neoleonés no aporta información y de igual manera, el número de propuestas efectivamente registradas como aprobadas supera los ciento cincuenta casos, mientras en Catalunya las ILP no rebasan los catorce casos. El número de propuestas ciudadanas en sentido estricto (ILP para Catalunya e ICL para Nuevo León) no implica un punto conmensurable para las variables aquí expuestas. No huelga hacer hincapié en las múltiples diferencias socio-políticas entre ambas entidades: en las importantes distinciones entre sus tradiciones, en atingencia a la esfera pública, así como en las condiciones disímiles de su localización geopolítica (la catalana, dentro de un país perteneciente a la Unión Europea y la neoleonesa, dentro de una república federal). De las peticiones cabe recordar que, tanto editadas en plazo como electrónicas, en Catalunya abarcaron 291, de las cuales 196 fueron por la vía electrónica. Como se ha referido, en Nuevo León no hay condiciones de gobierno electrónico para este tipo de participación ciudadana. Ninguna de las hipótesis permite aspectos completamente comparables entre las dos entidades: pues las dos primeras hipótesis sólo indagan una comparación de indicadores sin la agregación de variables propias de cada caso.

Por otra parte, al ser incomparables en varias propiedades jurídicas y procedimentales el Parlamento de Catalunya y la Legislatura de Nuevo León y teniendo presentes las aristas a debate del estado general de la cuestión que marcaron los objetivos de esta investigación, puede concluirse el cumplimiento de éstos.

Respecto al primer objetivo, se constata que la calidad estructural de un sistema jurídico para recibir propuestas ciudadanas estriba básicamente en dar radicación a dicho derecho. Ambos casos estudiados, con sus contrastes, dan cabida al derecho de participación ciudadana en su singularidad co-legislativa. Si bien, los derroteros procedimentales son arduos y, en opinión de los juristas (Soriano, 2012; Quintero, 2014; Vidal, 2015; Illueca, 2015; Fernández, 2019; Suárez y Welp, 2019), muy difíciles de satisfacer hasta feliz término. No obstante, las modalidades abarcan desde leyes y decretos hasta simples peticiones y puntos de acuerdo, es decir, un amplio abanico de posibilidades.

Con relación al segundo objetivo, la detección de la calidad ciudadana para formular sus postulaciones (al margen de su definitiva efectividad), el caso catalán muestra el indicador $\mathrm{D}_{1}$ óptimo en las ILP y aceptable para las peticiones, a excepción de la Legislatura XII. El indicador neoleonés muestra tendencia al punto óptimo en la mayoría de los casos. Dichas constataciones cumplen el objetivo propuesto.

\section{Conclusiones}

La indagación, organización y exposición de los "datos duros" en la estructuración científica tiene el compromiso de neutralidad. No obstante, las motivaciones de las preguntas de investigación, los objetivos y las hipótesis, no están exentas de intereses humanitarios, sociales y políticos. En la dimensión de esos intereses: el marco teórico, el referencial jurídico y 
resultados aquí descritos, deben trascender su neutralidad y atender la calidad de la democracia y también la calidad de la ciudadanía. Entendida la primera como la estructura e instrumentos que permiten la gobernanza, la colaboración entre ciudadanos y autoridades y el apoyo entre miembros de una comunidad para la toma de decisiones públicas y la segunda como el compromiso auto-didáctico de capacitación y participación ciudadana para involucrarse en la definición de las políticas públicas.

Declarar que los intereses subyacentes a la investigación deben trascender la neutralidad no significa que el procedimiento científico se sesga o parcializa, sino que, conservando su estatus epistemológico, se subordina a una finalidad superior. Es decir, en términos de Paquet se ha preferido "obtener respuestas no elegantes a buenas preguntas, en lugar de respuestas elegantes a preguntas sin sentido" (2009: 29). Amén de abandonar la soberbia intelectual, la buena pregunta que está en el fondo de estas reflexiones finales es: ¿qué tan democrática es la democracia según los indicadores de aceptación y éxito de las propuestas ciudadanas para normar la vida pública? La respuesta no elegante tiene dos dimensiones: los representantes políticos legislativos generalmente quedan bien calificados en sus tareas de atender, stricto sensu, las iniciativas ciudadanas. Sin embargo, el sistema democrático por lo regular no obtiene una nota aprobatoria en el quehacer comunitario de construir las políticas públicas. Por lo tanto, es ineludible la cuestión: ¿es correcto incluir en el sistema democrático instrumentos de participación ciudadana como las iniciativas legislativas? Los indicadores muestran otra respuesta no elegante: las iniciativas de ley no alcanzan los índices deseables del éxito final, no superan lo alto de la vara con que las miden los parlamentos. Este aspecto ha sido bien argumentado por Soriano: "La iniciativa legislativa popular [...] dejan mucho que desear en nuestro ordenamiento jurídico, porque las cautelas del constituyente y del legislador las han convertido en inaccesibles e impracticables por los ciudadanos [...] en la Comisión Mixta Congreso-Senado excluyeron de la iniciativa legislativa popular las materias de ley orgánica, precisamente las que mayor interés despiertan en los ciudadanos" (2002: 111-112).

En el sentido anterior, y a pesar de las reformas españolas del 2006 y las mexicanas más recientes de 2012 y 2014, "las limitaciones materiales de la ILP son muy amplias y constituyen la principal causa de inadmisibilidad, [por no corresponder] a un juicio político" (Martínez, 2012: 16). Las denominadas "respuestas no elegantes", no obstante el poco optimismo que provocan, representan sólo la dimensión de facto. Ante los intereses por ampliar la calidad de la democracia y la ciudadanía, develan oportunidades de jure. Entre éstas están, por parte de la ciudadanía; aprender a transitar de la visión particular de las peticiones hacia la mirada del interés general y el bien común propio del alcance universal de la ley; abocarse al aprendizaje auto- didáctico para elaborar iniciativas con mejores elementos jurídicos y argumentos más categóricos. De parte de las instituciones parlamentarias las áreas de oportunidades son muchas y muy significativas. Para el caso de Nuevo León, el Centro de Estudios Legislativos tiene la oportunidad de acercarse más a las condiciones de los ciudadanos para elevar sus inquietudes hasta el Congreso. Planes y programas de "mesas de trabajo" con las Organizaciones de la Sociedad Civil, 
colectivos, movimientos sociales y asociaciones son tareas que no se reflejan en la planeación y elaboración de los llamados "dictámenes". Por lo que corresponde al parlamento catalán es muy deseable una pronta actualización de las intenciones del Parlamento Abierto referentes al portal de transparencia y otros formatos electrónicos a los que hace alusión el artículo 228 de su respectivo Reglamento. De igual forma, la actualización y el trabajo colaborativo con el uso de las guías de participación y en particular de la guía de uso para las ILP debe concebirse como algo habitual.

Para finalizar estas reflexiones, en atingencia a la responsabilidad de los representantes legislativos con sus electores, cabe suscribir la puntualización de Soriano en su propuesta de la democracia armónica: "En cuanto a la iniciativa legislativa popular es necesaria una nueva iniciativa de creación legislativa del pueblo accesible y practicable, con un número de firmas ciudadanas razonable [para el caso español], sin el zancadilleo constante de los órganos de la democracia representativa (admisión a trámite y toma en consideración), con fijación legal del plazo para ser sustanciada y discutida en el Parlamento, [...] y defendida en el Pleno del Congreso por una representación de la comisión promotora de la iniciativa" (2012: 145). En el mismo sentido Illueca también concluye: “...parece necesario impulsar una reforma profunda de la ley reguladora en un triple sentido: a) regulación más abierta de la fase inicial, fijando sólo dos causas materiales de inadmisión: la incidencia sobre una materia excluida y la admisión previa, en el mismo año, de otra iniciativa sustancialmente idéntica; b) supresión del trámite de toma en consideración, equiparando su tramitación con la de los proyectos de ley; y c) apertura de cauces para una participación significativa de los promotores en la tramitación parlamentaria." (Illueca, 2015: 1138). Las últimas estipulaciones de Soriano e Illueca obedecen a evitar el riesgo de abandonar las iniciativas exclusivamente en manos de los parlamentarios, pues con ello se corre el peligro de arribar a una idea muy diferente de la intención inicial de sus promoventes. Así, en el compromiso recíproco entre ciudadanos y gobernantes para realizar la tarea co-legislativa, el factor clave está en asumir la asimetría de la reciprocidad entre parlamentarios y promoventes, sólo así se asegurará un mejor destino y el mayor éxito de las propuestas ciudadanas.

\section{Bibliografía}

Dahl, Robert (1993) La democracia y sus críticos, Barcelona, Paidós.

Departament de Relacions Institucionals i Participació de la Generalitat de Catalunya (2006) La Iniciativa legislativa popular: guia d'ús, Barcelona, Departament de Relacions Institucionals i Participació. Generalitat de Catalunya.

Direcció d'Estudis Parlamentaris, Parlament de Catalanya (2018) Resposta a la consulta 191138 a la Direcció d'Estudis Parlamentaris [comunicado electrónico Mercè Mateu Escoda] 4 octubre 2018 <direccioestudis@parlament.cat>

España. Constitución española 1978, de 29 de diciembre. (BOE [en línea], núm 311.1, 29-12-1978, pág. 29315-29342). <https://www. boe.es/eli/es/c/1978/12/27/ (1)/con>. [Consulta: 21 septiembre 2020]

España. Estatuto de Autonomía de Cataluña 2006, de 20 de julio. (BOE [en línea], núm. 172, 20-07-2006, pág. 27269-27310). <https://boe.es/boe/ 
dias/2006/07/20/pdfs/A27269-27310.pdf >. [Consulta: 21 septiembre 2020]

España. Reglamento del Parlamento de Cataluña 2006, de 14 de febrero. (BOE [en línea], núm. 38, 14.-12-2006, pág. 5777 -5812). <https://boe.es/boe/ dias/2006/02/14/pdfs/A05777-05812. pdf>. [Consulta: 21 septiembre 2020]

Estado libre y soberano de Nuevo León, México. Constitución política del Estado libre y soberano de Nuevo León 1917, 16 de diciembre. (Periódico Oficial del Estado, POE [en línea]), <http://www.hcnl.gob. mx/trabajo_legislativo/leyes/pdf/CONSTITUCION\%2OPOLITICA\%20DEL\%2OESTADO\%2OLIBRE\%20Y\%20SOBERANO\%20 DE\%2ONUEVO\%2OLEON.pdf>. [Consulta: 21 septiembre 2020]

Fernández, Ángel (2019) La iniciativa legislativa popular en el ordenamiento jurídico español, Tesis doctoral, Universidad de Salamanca.

Honorable Congreso del Estado de Nuevo León. Ley de Participación Ciudadana para el Estado de Nuevo León 2016, 13 de mayo. (Periódico Oficial del Estado, POE [en línea], núm 62, pág. 3-39), <http://sistec.nl.gob.mx/Transparencia_2015/Archivos/AC_0001_0007_00153989_000001. pdf $>$. [Consulta: 21 septiembre 2020]

Honorable Congreso del Estado de Nuevo León. Reglamento para el gobierno interior del Congreso del Estado de Nuevo León 1992, 16 de septiembre, con varias reformas (Periódico Oficial del Estado, POE) http://www.hcnl.gob.mx/trabajo_legislativo/ leyes/pdf/REGLAMENTO\%2OPARA\%20 EL\%2OGOBIERNO\%2OINTERIOR\%20 DEL\%20CONGRESO\%20DEL\%20ESTADO.pdf [Consulta: 21 septiembre 2020]

Honorable Congreso del Estado de Nuevo León. http://www.hcnl.gob.mx/trabajo_legislativo/iniciativas/ciudadanas.php [Consulta: 17 septiembre 2020]
Honorable Congreso del Estado de Nuevo León. http://www.hcnl.gob.mx/pdf/proceso_legislativo.pdf [Consulta: 17 septiembre 2020]

Honorable Congreso del Estado de Nuevo León. http://www.hcnl.gob.mx/trabajo_legislativo/informes.php [Consulta: 17 septiembre 2020]

Illueca, José (2015) "El derecho a la participación política directa. la iniciativa popular, realidad y posibilidades", Revista de Derecho UNED, No. 16, pp. 1095 - 1138 Kelsen, Hans (1977) Esencia y valor de la democracia, Madrid, Guadarrama.

Macpherson, Crawford Brough (1982) La democracia liberal y su época, Madrid, Alianza Editorial.

Manin, Bernard (1995) The Principles of Representative Government, Cambridge, Cambridge University Press.

Martí Mármol, Josep Lluís y Páez, José Ezequiel (2013) Guia d'instruments de participación ciutadana a Catalunya, Barcelona, Generalitat de Catalunya

Martínez, Aitor (2012) La iniciativa legislativa popular como instrumento de participación ciudadana en el siglo XXI, Madrid, Fundación IDEAS.

México. Constitución Política de los Estados Unidos Mexicanos 1917, de 5 de febrero (Diario Oficial de la Federación (DOF) [en línea] Tomo V, cuarta época, 5-2-1917, pág.149-161) <http://www.diputados. gob.mx/LeyesBiblio/ref/cpeum/CPEUM_ orig_05feb1917.pdf>. <http://www.diputados.gob.mx/LeyesBiblio/pdf/1_080520. pdf>. [Consulta: 21 septiembre 2020] Organización de Naciones Unidas (ONU) (1966) Pacto Internacional de Derechos Civiles y Políticos, Nueva York.

Pacto Internacional de Derechos Civiles y Políticos, Nueva York, 19 de diciembre de 1966. (BOE [en línea], núm. 103, 30-41977, pág. 9337-9343) <https://www.boe. es/boe/dias/1977/04/30/pdfs/A09337- 
09343.pdf>. [Consulta: 21 septiembre 2020]

Pacto Internacional de Derechos Civiles y Políticos, Nueva York, 19 de diciembre de 1966. (Diario Oficial de la Federación (DOF) [en línea], tomo CCCLXVI, núm.12, 20-5-1981 pág. 5-13). <https://www.dof. gob.mx/nota_to_imagen_fs.php?cod_diari $0=200129$ \&pagina $=5 \&$ seccion $=1>$. [Consulta: 21 septiembre 2020]

Paquet, Gilles (2009), Crippling Epistemologies and Governance Failures: A Plea for Experimentalism, Ottawa, University of Ottawa Press.

Parlament de Catalunya. Recuperado de: https://www. parlament.cat/web/index.html [Consulta: entre el 20 de enero de 2019 y el 29 de junio de 2019]

Parlament de Catalunya. https://www.parlament.cat/web/activitat-parlamentaria/ iniciatives-legislatives/iniciativa-legislativapopular-ilp/index.html [Consulta: entre el 20 de enero de 2019 y el 29 de junio de 2019]

Parlament de Catalunya. https://www.parlament.cat/web/activitat-parlamentaria/ Ileis/index.html [Consulta: entre el 20 de enero de 2019 y el 29 de junio de 2019]

Parlament de Catalunya. Sistema de Información de la Actividad Parlamentaria (SIAP) https://www.parlament.cat/web/activitat-parlamentaria/siap/index.html [Consulta: entre el 20 de enero de 2019 y el 29 de junio de 2019]

Parlament de Catalunya https://www.parlament.cat/web/participacio/epeticions/index.html [Consulta: entre el 20 de enero de 2019 y el 29 de junio de 2019]

Parlament de Catalunya. https://www. parlament.cat/web/participacio/esco-136/index.html [Consulta: entre el 20 de enero de 2019 y el 29 de junio de 2019]

Parlament de Catalunya. Glossari de termes relacionats amb la tramitació parlamentària. https://www. parlament.cat/do- cument/ects/173016.pdf [Consulta: entre el 20 de enero de 2019 y el 29 de junio de 2019]

Pizzorusso, Alessandro (1980) "Democrazia participativa e attivitá parlamentare", en AA.VV. Parlamento, Istituzioni e Democrazia, Milano, Giuffrè

Przeworski, Adam (1998) "Democracia y representación", Reforma y Democracia, Revista del CLAD, No. 10, pp. 7-44.

Saura y Laporta, Joan (2006) "Presentació", en Departament de Relacions Institucionals i Participació de la Generalitat de Catalunya (eds.), La Iniciativa legislativa popular: guia d'ús Barcelona, Departament de Relacions Institucionals i Participació, Generalitat de Catalunya, pp. 2-3.

Schumpeter, Joseph (1976) Capitalism, Socialism and Democracy, London, Allem and Unwin.

Soriano, Ramón (2002) "La iniciativa legislativa popular: una institución herida de muerte", Sistema, No.16, pp.111-118.

Soriano, Ramón (2012) "La democracia armónica: la conjunción equilibrada de los modelos democráticos", Anales de la Cátedra Francisco Suárez, No. 46, pp. 135154.

Suárez, Orestes y Welp, Yanina (2019) "¿Papel mojado? Análisis de la Iniciativa Legislativa Popular en Colombia", Estudios Políticos, No. 54, pp. 106-126.

Vintró, Joan (2011) "Un punto de partida: el marco normativo de la Iniciativa Legislativa Popular en España", en Pajares Montolío, Emilio (coord.). Participación ciudadana y procedimiento legislativo: de la experiencia española a la iniciativa ciudadana europea, Madrid, Centro de Estudios Políticos y Constitucionales

Welp, Yanina, et. al (2018) ¿Firmar para influir en política? Modelos y experiencias de iniciativa ciudadana local, Barcelona, Ajuntament de Barcelona. 